\title{
A New Kind of Circular Polarization Leaky-Wave Antenna Based on Substrate Integrated Waveguide
}

\author{
Chong Zhang, ${ }^{1,2}$ Junhong Wang, ${ }^{1,2}$ Meie Chen,,2 Zhan Zhang, ${ }^{1,2}$ and Zheng $\mathrm{Li}^{1,2}$ \\ ${ }^{1}$ Key Laboratory of All Optical Network \& Advanced Telecommunication Network of MOE, Beijing Jiaotong University, \\ Beijing 100044, China \\ ${ }^{2}$ Institute of Lightwave Technology, Beijing Jiaotong University, Beijing 100044, China
}

Correspondence should be addressed to Chong Zhang; cynthia09111007@163.com

Received 11 September 2014; Revised 25 December 2014; Accepted 25 December 2014

Academic Editor: Wei Hong

Copyright (C) 2015 Chong Zhang et al. This is an open access article distributed under the Creative Commons Attribution License, which permits unrestricted use, distribution, and reproduction in any medium, provided the original work is properly cited.

\begin{abstract}
A new kind of circular polarization leaky-wave antenna with $\mathrm{N}$-shaped slots cut in the upper side of substrate integrated waveguide (SIW) is investigated and presented. The radiation pattern and polarization axial ratio of the leaky-wave antenna are studied. The results show that the width of $\mathrm{N}$-shaped slots has significant effect on the circular polarization property of the antenna. By properly choosing structural parameters, the SIW based leaky-wave antenna can realize circular polarization with excellent axial ratio in $8 \mathrm{GHz}$ satellite band.
\end{abstract}

\section{Introduction}

Circular polarization antennas have been widely used in areas of satellite communication, mobile communication, radar, remote, and so forth. They can reduce the effects of multipath interference, rain and fog interference, and polarization mismatch in radars and communication systems [1]. There are several kinds of waveguide structures used in design of leakywave antennas for generating circular polarization wave, such as the rectangular waveguide with two compound slots cut in top wall [2]. However, for the rectangular waveguide based leaky-wave antenna, it is difficult to integrate with other circuits. Considering the merits of low cost, light weight, low profile, and easy fabrication by PCB or similar processes $[3,4]$, the substrate integrated waveguide (SIW) is now widely used in design of SIW leaky-wave antennas [59]. However, most of the available leaky-wave antennas are designed for radiating linear polarization wave; only a few works concerning circular polarization can be found [10], especially for $\mathrm{C}$ band satellite communication (from $7 \mathrm{GHz}$ to $8 \mathrm{GHz}$ ).

In this paper, a new kind of circular polarization leakywave antenna based on substrate integrated waveguide with $\mathrm{N}$-shaped slots is proposed. Simulation and measurement results show that this kind of structure can realize circular polarization radiation in $8 \mathrm{GHz}$ satellite band by choosing proper parameters for the $\mathrm{N}$-shaped slots.

\section{Antenna Design}

The substrate integrated waveguide can be equivalent to the conventional rectangular waveguide, where the periodic metallic vias in SIW are considered as the side wall of conventional waveguide. Therefore, the SIW with $\mathrm{N}$-shaped slots proposed in this paper can be equivalent to a dielectric filled rectangular waveguide with $\mathrm{N}$-shaped slots cut in top wall of the waveguide [3].

The geometry of the SIW leaky-wave antenna with Nshaped slots for $8 \mathrm{GHz}$ band is shown in Figure 1. The antenna is designed on a substrate of Rogers Duroid 5880 with a relative permittivity of 2.2 and a thickness of $1.57 \mathrm{~mm}$ and is fed by a microstrip line with impedance of $50 \Omega$ from one end. The other end of the antenna is terminated by matching load to maintain a traveling-wave state. The diameter and period of metallic vias are set to $0.8 \mathrm{~mm}$ and $1.2 \mathrm{~mm}$, respectively, and the distance between two rows of metallic vias is set to $15.5 \mathrm{~mm}$. According to formulas given in [3], the cutoff frequencies for the dominant and first higher order modes 


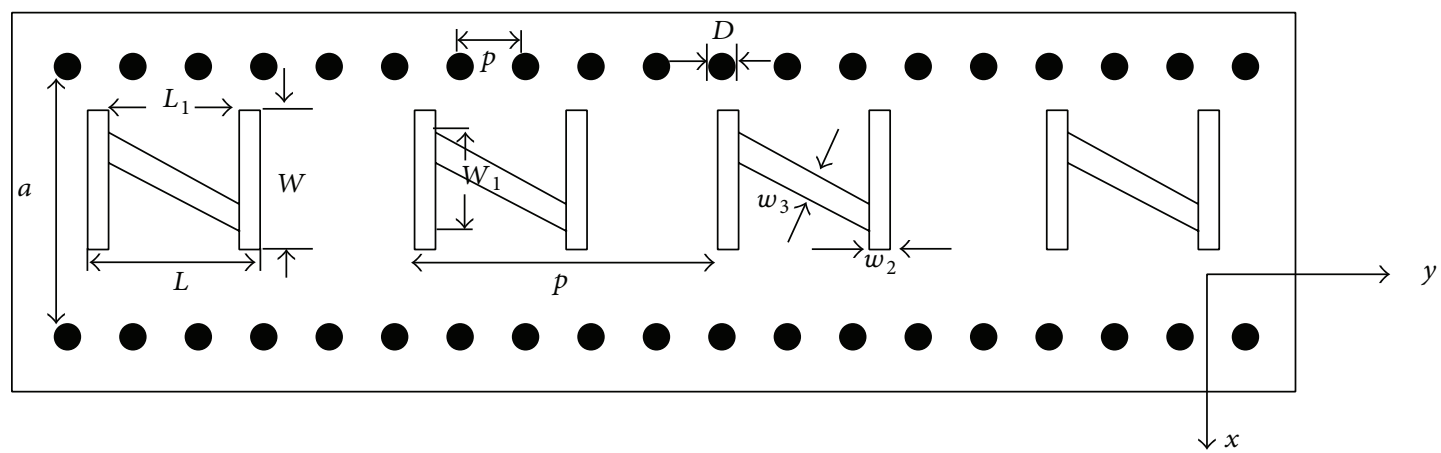

FIGURE 1: Geometry of the N-shaped slotted SIW: $a=15.5 \mathrm{~mm}, \varepsilon_{r}=2.2, p=1.2 \mathrm{~mm}, D=0.8 \mathrm{~mm}, w_{2}=0.5 \mathrm{~mm}$, and $w_{3}=0.6 \mathrm{~mm}$.

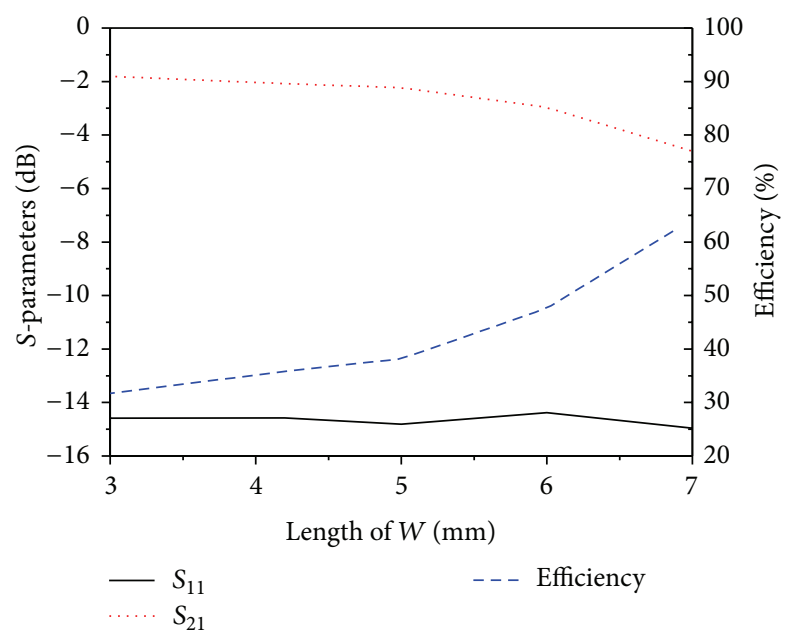

FIGURE 2: S-parameters of the SIW leaky-wave antenna as functions of width of the $\mathrm{N}$-shaped slot, $f=8 \mathrm{GHz}$.

of this SIW are $6.8 \mathrm{GHz}$ and $13.6 \mathrm{GHz}$, respectively, so for $8 \mathrm{GHz}$ satellite band only $\mathrm{TE}_{10}$ mode can be transmitted in it. There are total $29 \mathrm{~N}$-shaped slots etched along the center line of SIW with a period of $10 \mathrm{~mm}$, and the total length of SIW is $380 \mathrm{~mm}$; these slots form the dominant radiation section of the SIW as shown in Figure 1. The operating frequency is $8 \mathrm{GHz}$.

As we know, the transverse slot in waveguide wall cuts the current flowing in longitudinal direction, while the longitudinal slot cuts the current flowing in transverse direction. Therefore, only transverse slot or longitudinal slot cannot generate circular polarization radiation. Since Nshaped slot is composed of both transverse and longitudinal slots, it can cut the currents flowing in both longitudinal and transverse directions at the same time. Therefore, $\mathrm{N}$-shaped slots possibly generate circular polarization wave.

As can be seen in Figure 1, the parameters of N-shaped slots in this paper include the length $L$ and width $W$ of the letter "N" and the length $L_{1}$ and width $W_{1}$ of the inclined slot. The circular polarization property of the antenna depends on these parameters of slots.

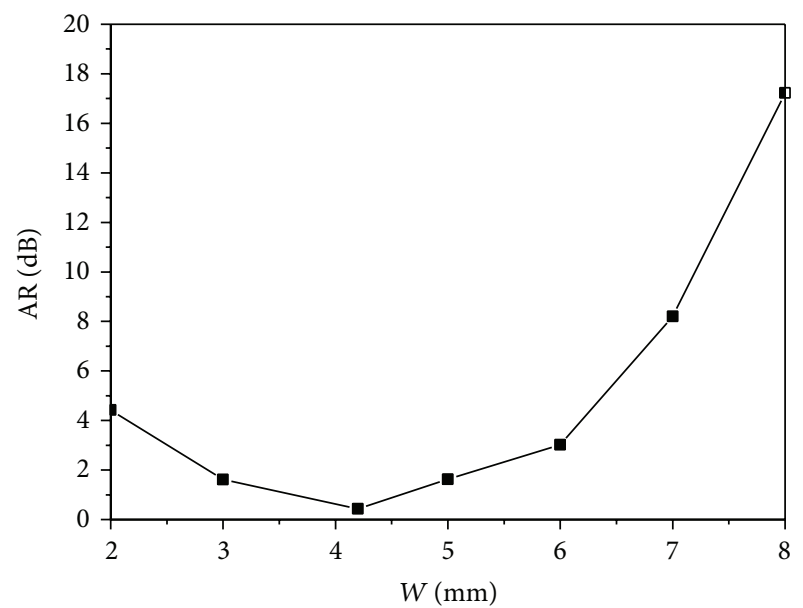

FIgURE 3: Axial ratio of the SIW leaky-wave antenna as function of length $W$ of the $\mathrm{N}$-shaped slot for $f=8 \mathrm{GHz}, L=5 \mathrm{~mm}, L_{1}=$ $4 \mathrm{~mm}$, and $W_{1}=3.2 \mathrm{~mm}$.

\section{Results and Discussion}

3.1. S-Parameters and Attenuation Constant. Figure 2 illustrates the $S$-parameters and radiation efficiency of the SIW leaky-wave antenna as functions of width $W$ of slots at frequency of $8 \mathrm{GHz}$; the other parameters of the slots are fixed to $L=5 \mathrm{~mm}, L_{1}=4 \mathrm{~mm}$, and $W_{1}=3.2 \mathrm{~mm}$. The attenuation constant $\alpha$ along antenna and the radiation efficiency can be calculated by the following expressions:

$$
\begin{gathered}
\alpha=-\frac{1}{2 L_{\mathrm{SIW}}} \ln \left(\frac{\left|S_{21}\right|^{2}}{1-\left|S_{11}\right|^{2}}\right), \\
\eta_{\mathrm{eff}}=\frac{P_{\mathrm{rad}}}{P_{\mathrm{acc}}}=\frac{1-\left|S_{11}\right|^{2}-\left|S_{21}\right|^{2}}{1-\left|S_{11}\right|^{2}},
\end{gathered}
$$

where $L_{\text {SIW }}$ is the length of the radiation section of SIW, $P_{\text {rad }}$ is the radiated power, and $P_{\text {acc }}$ is the accepted power. It should be noticed that the leakage rate depends on the length of $\mathrm{N}$ shaped slot, so the attenuation constant $\alpha$ increases with the length of slot. In addition, the radiation efficiency of antenna increases with total length of radiation section of the antenna but also changes with other parameters of the slots. 


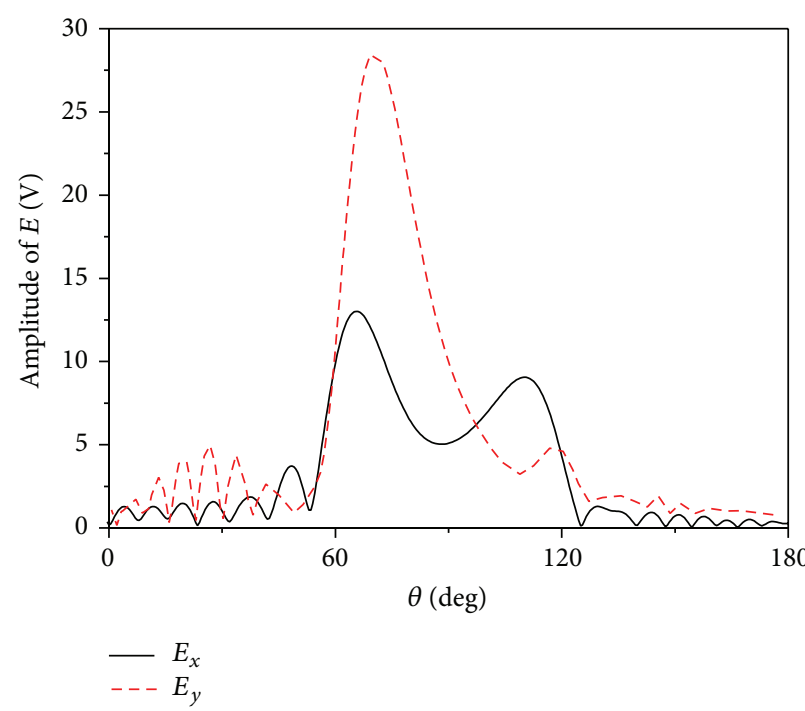

(a)

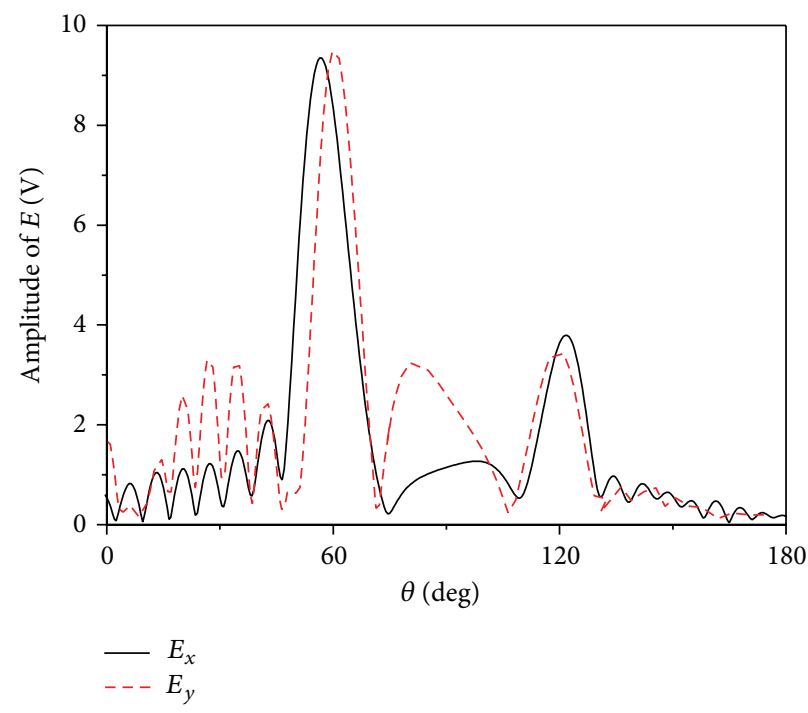

(b)

FIGURE 4: Amplitudes of the two electrical field components radiated by the SIW leaky-wave antenna for different lengths of N-shaped slots, $f=8 \mathrm{GHz}, L=5 \mathrm{~mm}$, (a) $W=6 \mathrm{~mm}$, and (b) $W=4.2 \mathrm{~mm}$.

3.2. Effect of Structure Parameters on Axial Ratio. Since the period of slots is set to $P=10 \mathrm{~mm}$, the range of slot lengths should be limited to $2 \mathrm{~mm}$ and $7 \mathrm{~mm}$. In order to decrease the intersection between adjacent slots, the length of slot is fixed to $L=5 \mathrm{~mm}$ in this paper.

Considering the conditions for generating circular polarization wave, the range of slot widths is set to $2 \mathrm{~mm}$ and $8 \mathrm{~mm}$. Figure 3 illustrates the effect of width $W$ of $\mathrm{N}$-shaped slots on the axial ratio, while $W_{1}=3.2 \mathrm{~mm}$ and $L_{1}=4 \mathrm{~mm}$, from which we can see that the axial ratio is influenced significantly by the width $W$. In order to find the reason behind this phenomenon, the amplitudes of the two components $E_{x}$ and $E_{y}$ of far field for two cases of $W=4.2 \mathrm{~mm}$ and $W=6 \mathrm{~mm}$ are given in Figure 4. It can be found that when $W=4.2 \mathrm{~mm}$, the amplitude of $E_{x}$ almost equals that of $E_{y}$, but for $W=6 \mathrm{~mm}$ $E_{x}$ is much smaller than $E_{y}$. In addition, the increasing of width of $\mathrm{N}$-shaped slots will cut more $J_{y}$ current filaments; therefore, $E_{y}$ will increase and ratio of $E_{x} / E_{y}$ will decrease; this results in a significant change in the axial ratio.

While the width of $\mathrm{N}$-shaped slots is fixed to $W=$ $4.2 \mathrm{~mm}$, the axial ratio as function of length $L_{1}$ is given in Figure 5; the length of $L$ is fixed to $5 \mathrm{~mm}$. Because the width $w_{2}$ of two vertical slots is set to $0.5 \mathrm{~mm}$ in this paper, the $\mathrm{N}$-shaped slot structure keeps unchanging when horizontal length of inclined slots $L_{1}$ increases from $4 \mathrm{~mm}$ to $5 \mathrm{~mm}$; this corresponds to the straight segment in the bottom of the curve. From Figure 5, it can be found that when the length $L$ of the slots is larger than that of the inclined slot $L_{1}$, the axial ratio increases sharply. On the other hand, the axial ratio of the antenna increases gently, when the length of inclined slot $L_{1}$ is larger than $L$.

Figure 6 illustrates the electric field distributions of the $\mathrm{N}$-shaped slot for parameters of $L_{1}=3 \mathrm{~mm}\left(L_{1}+2 w_{2}<L\right)$ and $L_{1}=4 \mathrm{~mm}\left(L_{1}+2 w_{2}=L\right)$, respectively, from which we find that the field component $E_{y}$ for $L_{1}=3 \mathrm{~mm}$ is much

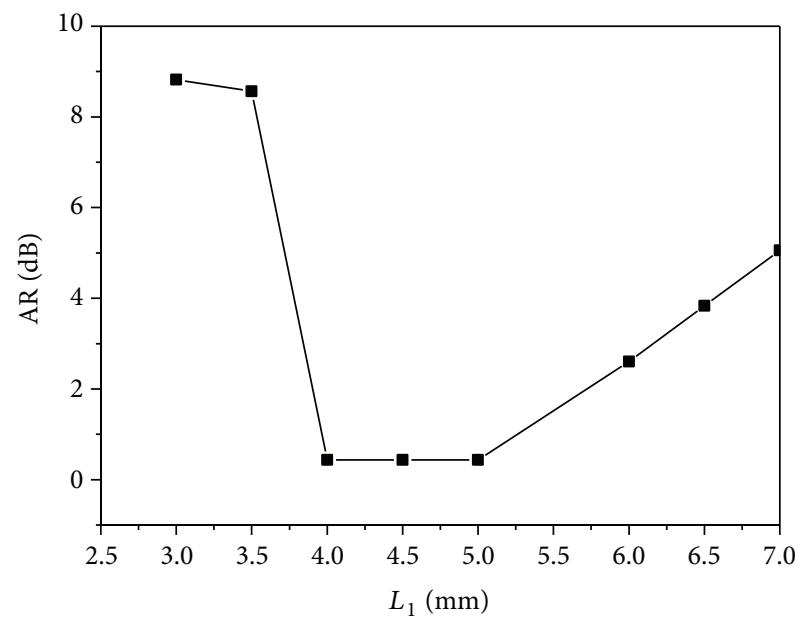

FIGURE 5: Axial ratio of the SIW leaky-wave antenna as function of length $L_{1}$ of the N-shaped slot for $f=8 \mathrm{GHz}, L=5 \mathrm{~mm}, W=$ $4.2 \mathrm{~mm}$, and $W_{1}=3.2 \mathrm{~mm}$.

larger than that of $L_{1}=4 \mathrm{~mm}$. The reason is that more current filaments are cut by the left and right edges of the two vertical slots and inclined slot when $L_{1}=3 \mathrm{~mm}\left(L_{1}+2 w_{2}<L\right)$, as can be seen in Figure 6. Figure 7 shows the axial ratios of the antenna in main beam direction for different widths $W_{1}$ of inclined slot. It can be found that changing of width $W_{1}$ has little impact on the axial ratio.

3.3. Antenna with Optimum Circular Polarization Property. According to the above analysis, properly selecting parameters of $\mathrm{N}$-shaped slots can give minimum axial ratio in main beam direction of the antenna for a specific frequency band. From our work, it is found that when the parameters 


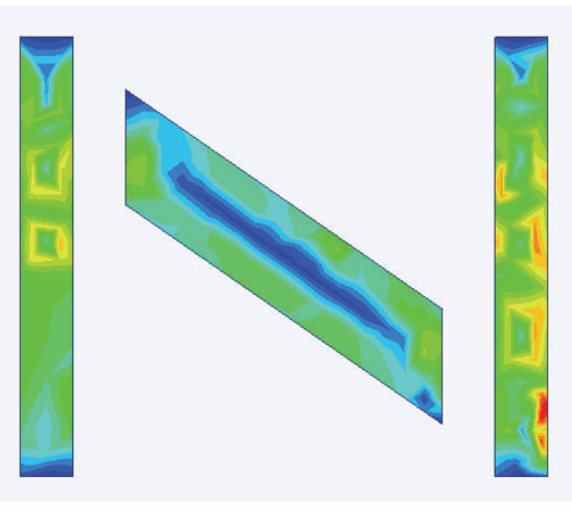

(a) $L_{1}=3 \mathrm{~mm}$

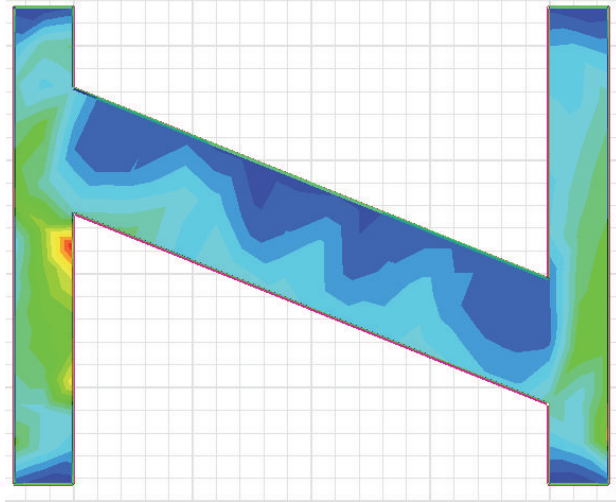

(b) $L_{1}=4 \mathrm{~mm}$

FIGURE 6: Magnitude distribution of $E_{y}$ in the N-shaped slot.

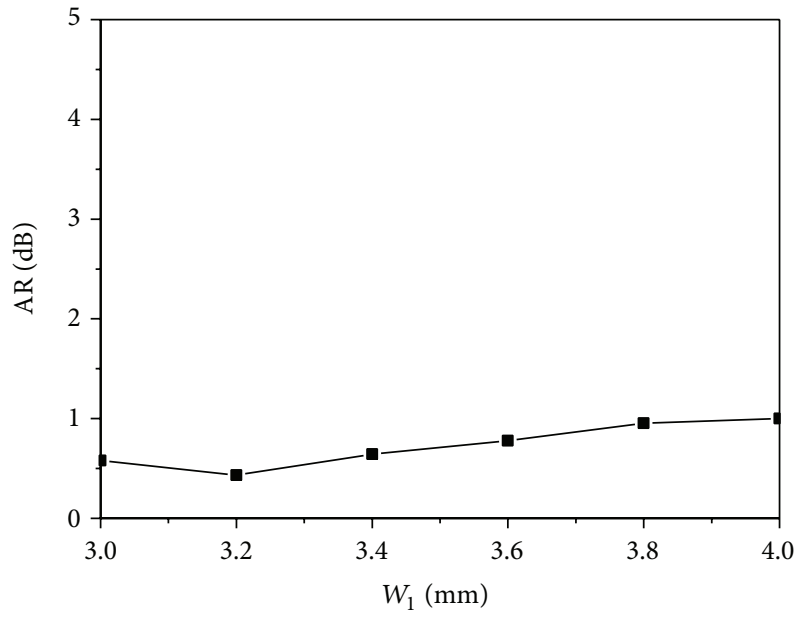

FIGURE 7: Axial ratio of the SIW leaky-wave antenna as function of width $W$ of the N-shaped slot for $f=8 \mathrm{GHz}, L_{1}=4 \mathrm{~mm}, L=5 \mathrm{~mm}$, and $W=4.2 \mathrm{~mm}$.

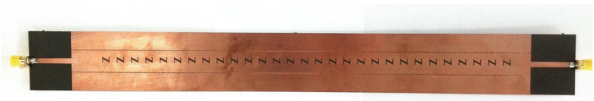

Figure 8: Photograph of the SIW with N-shaped slots.

of $\mathrm{N}$-shaped slots are selected to be $W=4.2 \mathrm{~mm}, W_{1}=$ $3.2 \mathrm{~mm}, L=5 \mathrm{~mm}$, and $L_{1}=4 \mathrm{~mm}$, the axial ratio reaches its minimum value of 0.443 at $8 \mathrm{GHz}$. The photograph of the fabricated antenna corresponding to these parameters is shown in Figure 8. The measured and simulated $S$-parameters of the antennas are illustrated in Figure 9. It can be found that the simulated and experimented return losses of the antenna are lower than $-10 \mathrm{~dB}$ from $7.6 \mathrm{GHz}$ to $8.2 \mathrm{GHz}$. The differences between simulated and measured results are probably due to the errors of fabrication and measurement. Meanwhile, the measured $S_{21}$ is a little bit smaller than the simulated one, because the loss of feeders and dielectric substrate are not considered during the simulation.

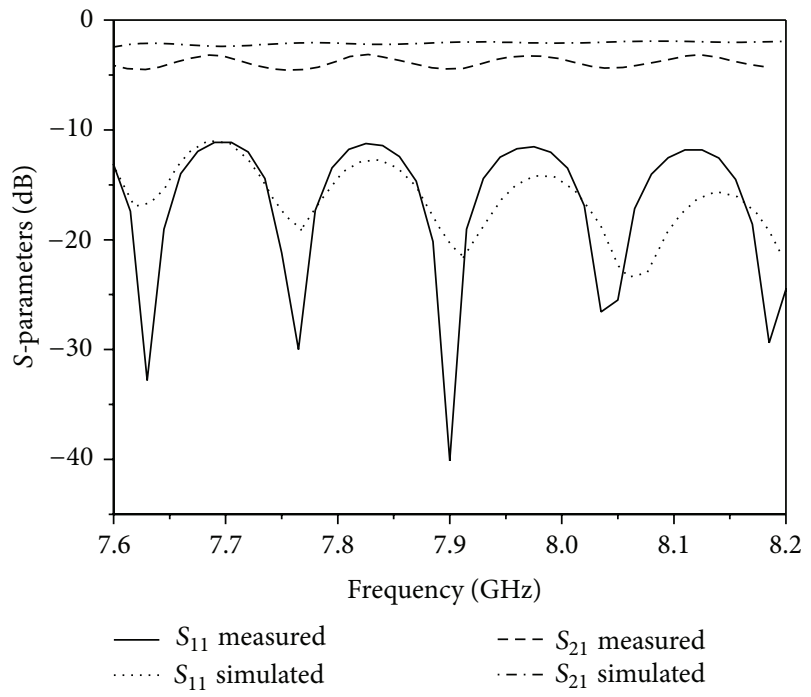

FIgURE 9: Measured and simulated $S$-parameters of the antenna shown in Figure 8.

The axial ratios of antennas for different widths in main beam direction as functions of frequency are given in Figure 10. It can be found that, for $W=4.2 \mathrm{~mm}$, the simulated axial ratio is less than $3 \mathrm{~dB}$ in the band from $7.6 \mathrm{GHz}$ to $8.2 \mathrm{GHz}$, and the measured axial ratio is less than $5 \mathrm{~dB}$ in this band. When the slot width is increased to $6 \mathrm{~mm}$, the axial ratio of the corresponding antenna is larger than that of the antenna with $W=4.2 \mathrm{~mm}$; this phenomenon can be explained by Figure 4 . The comparisons of axial ratios of the antenna with $\mathrm{N}$-shaped slots and the antenna with $\mathrm{H}$ shaped slot given in [9], in band from $7.6 \mathrm{GHz}$ to $8.2 \mathrm{GHz}$, are also given in Figure 10. It can be found that the axial ratio of antenna with $\mathrm{N}$-shaped slot is lower than that of antenna with $\mathrm{H}$-shaped slot at specific frequency band.

Figure 11 gives the simulated and measured radiation patterns at $8 \mathrm{GHz}$, when the antenna is fed from left side. It can be found that the antenna generates right-hand circular polarization wave; the simulated gain is $8.93 \mathrm{dBi}$, and the gain 


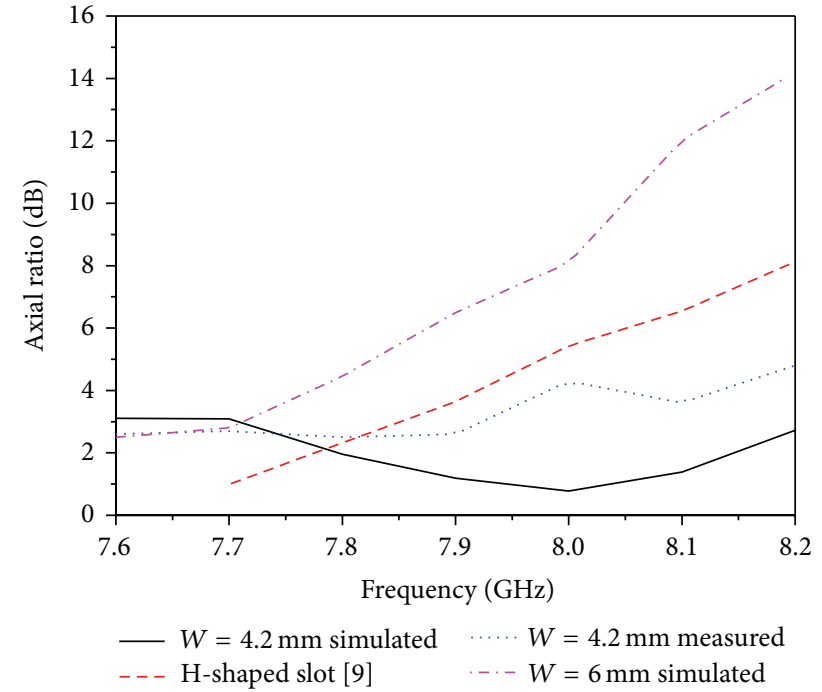

FIgURE 10: Comparisons of axial ratios of the antennas with Nshaped slots and the antenna with $\mathrm{H}$-shaped slot given in [9].

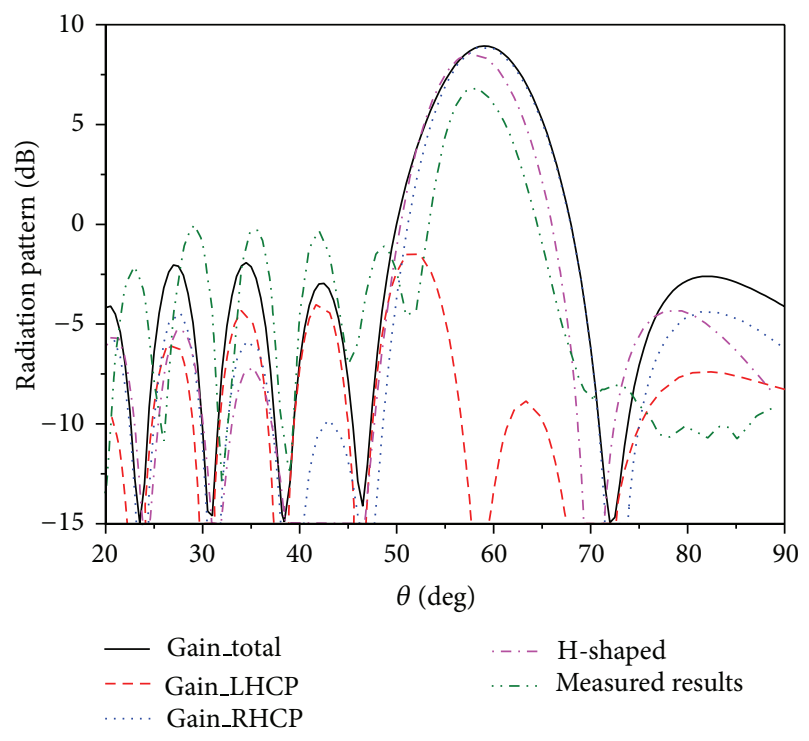

FIGURE 11: Radiation patterns of the SIW leaky-wave antennas fed from left side.

for the left-hand circular polarization wave (cross polarization) of this antenna is $-1.36 \mathrm{dBi}$, which is about $10.3 \mathrm{dBi}$ lower than that of RHCP; measured gain is lower than the simulated result. The gain of the antenna in [9] for $\mathrm{H}$-shaped slots is also given in Figure 11, which is $0.4 \mathrm{dBi}$ lower than that of the antenna with $\mathrm{N}$-shaped slots.

It is found from analysis that when the antenna is fed from the right side, the left-hand circular polarization (LHCP) radiation will be generated, as shown in Figure 12. The gain for the LHCP wave is $10.82 \mathrm{dBi}$ higher than that of RHCP wave. The axial ratio of the antenna fed from right side is given in Figure 13. It can be found that the range for axial ratio less than $3 \mathrm{~dB}$ is $56.5^{\circ}$ and $63.5^{\circ}$.

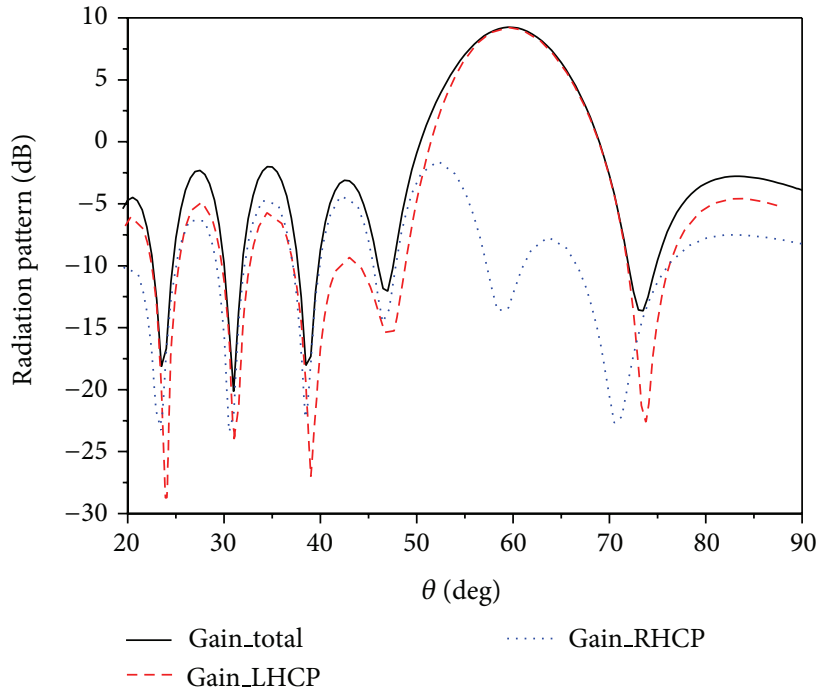

FIGURE 12: Radiation patterns of the SIW leaky-wave antennas fed from right side.

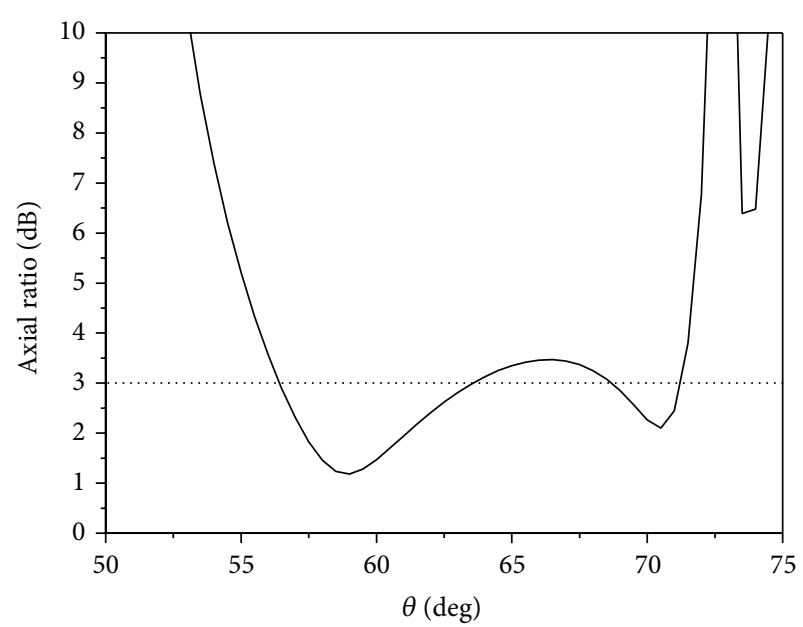

Figure 13: Axial ratio of the antenna fed from right side.

\section{Conclusion}

In this paper, a novel kind of circular polarization leaky-wave antenna with $\mathrm{N}$-shaped slots based on substrate integrated waveguide is proposed, and the axial ratios for different parameters and frequencies are given and discussed. From the simulated and measured results, it is found that this SIW based leaky-wave antenna can realize circular polarization radiation in the $8 \mathrm{GHz}$ satellite band, and it maintains the desirable properties of low profile and light weight and is easy to integrate with planar circuits.

\section{Conflict of Interests}

The authors declare that there is no conflict of interests regarding the publication of this paper. 


\section{Acknowledgments}

This work was supported in part by the National Nature Science Foundation of China under Grant 61331002 and in part by the National Program on Key Basic Research Project under Grant no. 2013CB328903.

\section{References}

[1] G. Q. Luo, P. Li, Z. C. Zheng, and L. L. Sun, "A dual circularly polarized antenna with improved axial ratio bandwidth," in Proceedings of the China-Japan Joint Microwave Conference (CJMW'11), pp. 179-182, April 2011.

[2] G. Mazzarella, Q. Mootisci, and M. Musa, "A polarization-agile waveguide slot antenna," in Proceedings of the IEEE Antennas and Propagation Society International Symposium, vol. 3, pp. 1034-1037, June 2003.

[3] D. Deslandes and K. Wu, "Integrated microstrip and rectangular waveguide in planar form," IEEE Microwave and Wireless Components Letters, vol. 11, no. 2, pp. 68-70, 2001.

[4] K. Wu and F. Boone, "Guided-wave properties of synthesized nonradiative dielectric waveguide for substrate integrated circuits (SICs)," in Proceedings of the IEEE MTT-S International Microwave Symposium Digest, vol. 2, pp. 723-726, 2001.

[5] T. Yang, P. L. Chi, and R. M. Xu, "Novel composite right/lefthanded leaky-wave antennas based on the folded substrate integrated waveguide structures," Progress In Electromagnetics Research C, vol. 29, pp. 235-248, 2012.

[6] L. Yan, W. Hong, G. Hua, J. Chen, K. Wu, and T. J. Cui, "Simulation and experiment on SIW slot array antennas," IEEE Microwave and Wireless Components Letters, vol. 14, no. 9, pp. 446-448, 2004.

[7] W. Hong, "Development of microwave antennas, components and subystems based on SIW technology," in Proceedings of the IEEE International Symposium on Microwave, Antenna, Propagation and EMC Technologies for Wireless Communications (MAPE '05), pp. 14-17, August 2005.

[8] J. Liu, D. R. Jackson, and Y. Long, "Substrate integrated waveguide (SIW) leaky-wave antenna with transverse slots," IEEE Transactions on Antennas and Propagation, vol. 60, no. 1, pp. 20 29, 2012.

[9] Y. J. Li and K.-M. Luk, "Low-cost high-gain and broadband substrate-integrated-waveguide-fed patch antenna array for 60$\mathrm{GHz}$ band," IEEE Transactions on Antennas and Propagation, vol. 62, no. 11, pp. 5531-5538, 2014.

[10] J. H. Liu, X. H. Tang, Y. X. Li, and Y. L. Long, "Substrate integrated waveguide leaky-wave antenna with $\mathrm{H}$-shaped slots," IEEE Transactions on Antennas and Propagation, vol. 60, no. 8, pp. 3962-3967, 2012. 

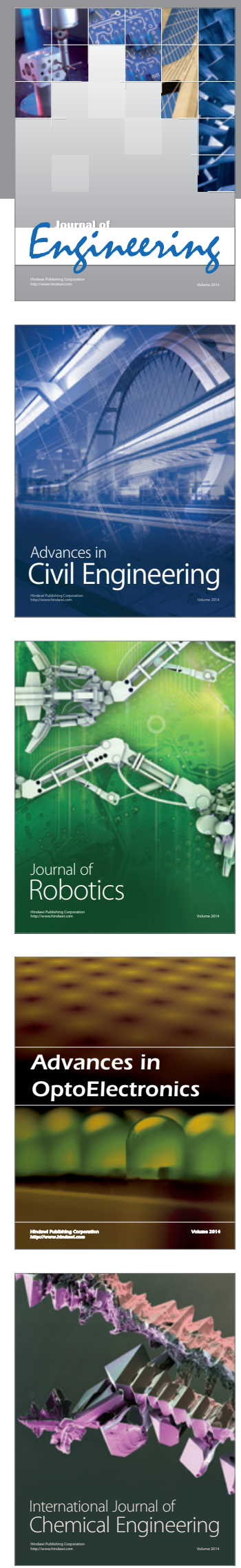

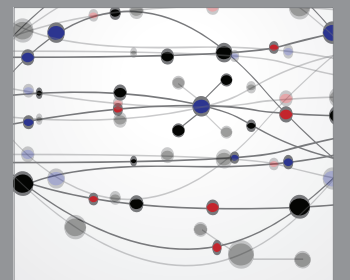

The Scientific World Journal
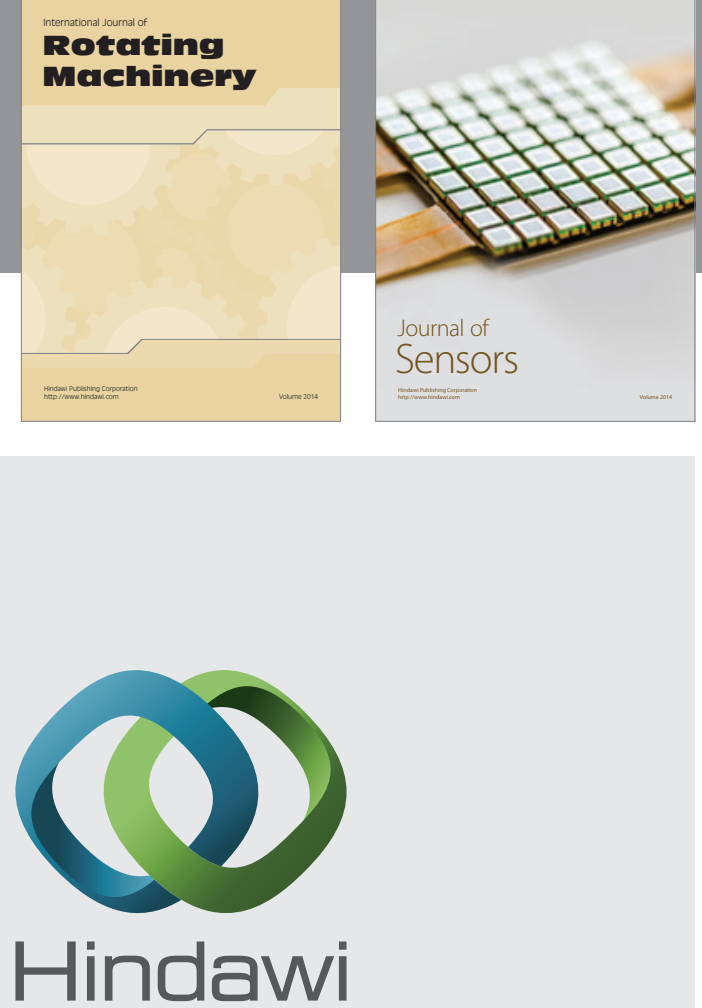

Submit your manuscripts at http://www.hindawi.com
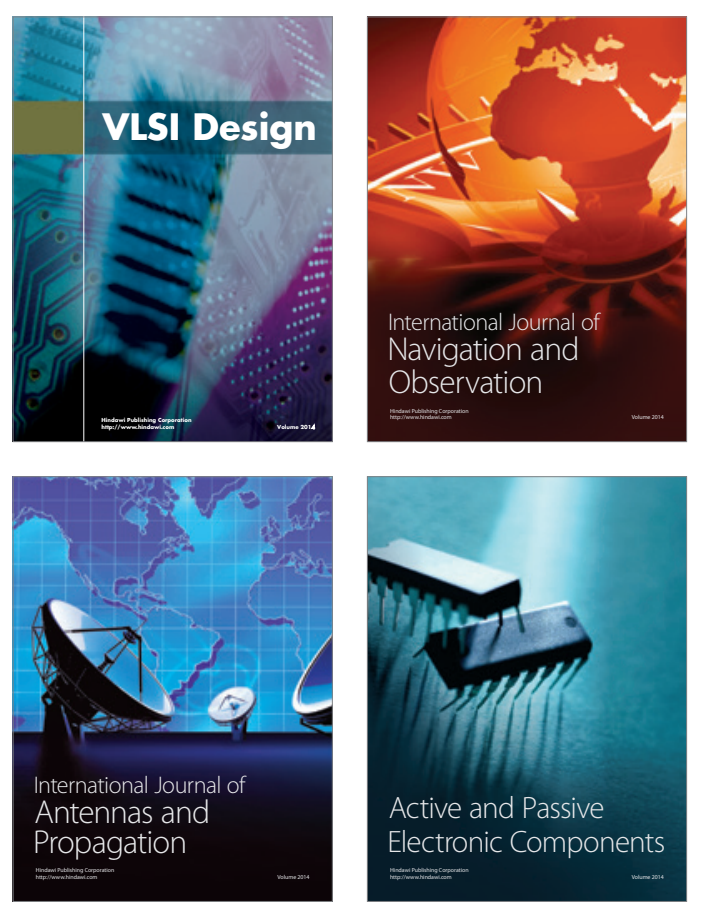
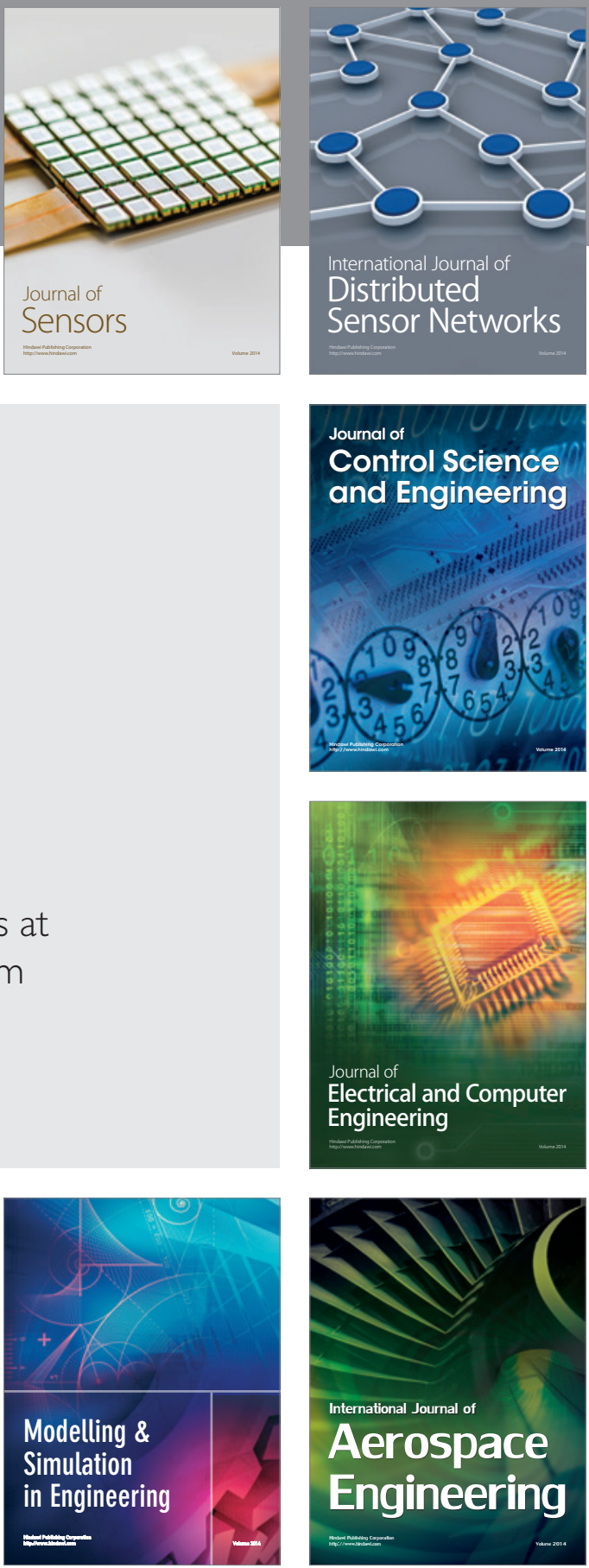

Journal of

Control Science

and Engineering
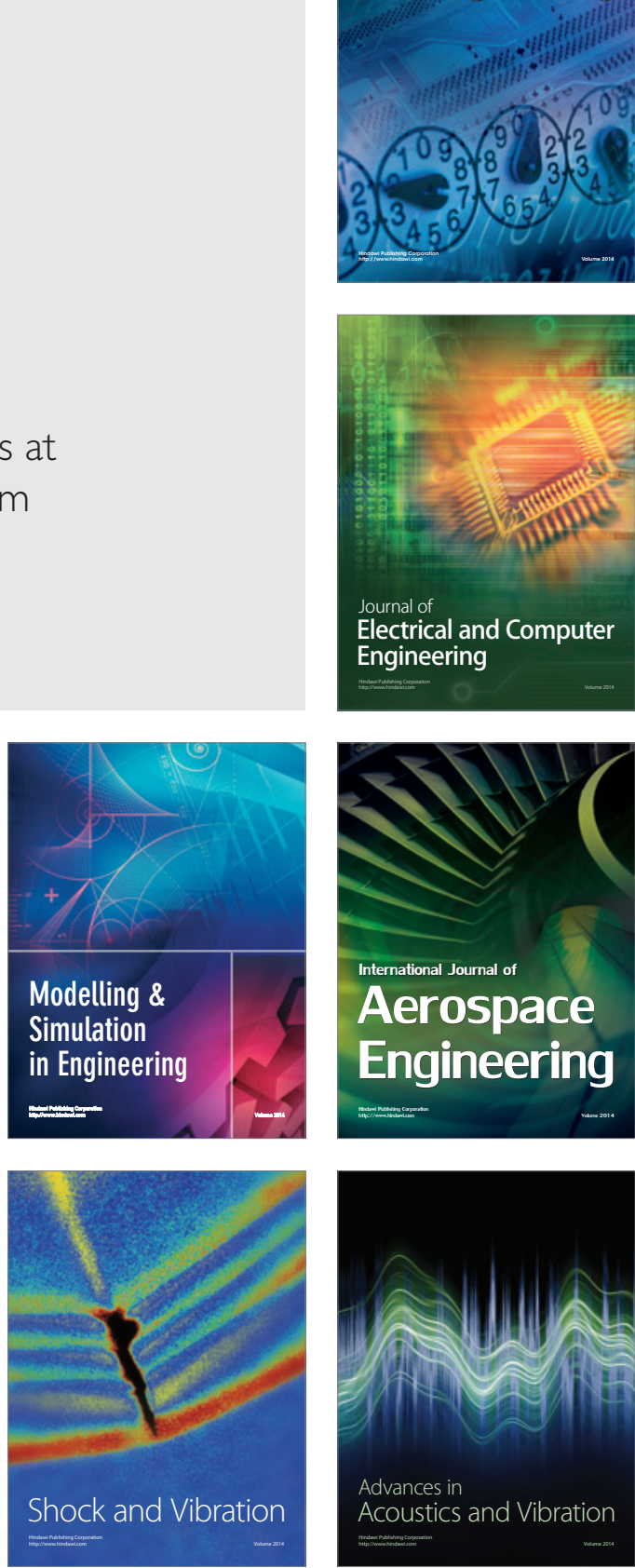